\title{
Türkiye'de ticari çift kabuklu yumuşakça avcılığında kullanılan av araçları
}

\section{The fishing gear used in commercial bivalve fishery in Turkey}

\author{
Serhat Çolakoğlu1* (D) Adnan Tokaç² \\ 1 Çanakkale Onsekiz Mart Üniversitesi, Teknik Bilimler Meslek Yüksekokulu, Gıda İşleme, 17020, Çanakkale, Türkiye \\ 2 Ege Üniversitesi, Su Ürünleri Fakültesi, Avlama ve İşleme Teknolojisi Bölümü, 35100, Bornova, İzmir, Türkiye \\ *Corresponding author. serhat_colakoglu@comu.edu.tr
}

\section{How to cite this paper:}

Çolakoğlu, S. \& Tokaç, A. (2017). The fishing gear used in commercial bivalve fishery in Turkey. Ege Journal of Fisheries and Aquatic Sciences, 34(4):415-421. doi: 10.12714/egejfas.2017.34.4.08

Öz: Bu çalışmada, Türkiye'nin Batı Karadeniz, Marmara Denizi ve Ege Denizi kıyısal alanlarında, çift kabuklu yumuşakçaların ticari avcıı̆ı̆ında kullanılan av araçlarının teknik özellikleri ile avclık yöntemlerinin genel özellikleri tespit edilmiştir. Avcllık dalarak, kıyıdan insan gücü ve tekne gücü ile olmak üzere üç ana bölümde değerlendirilmiş, türe özel 8 tipte av aracı ve yöntemi belirlenmiş̧tir. Araştırma bölgelerinde sekiz adet kama, beş adet el tırmığı, sekiz adet elekli kürek, on üç adet el dreci, üç adet istiridye dreci, dört adet kara midye dreci, dokuz adet mekanik dreç ve yedi adet hidrolik dreç olmak üzere toplam elli yedi adet av aracı saptanmış̧ır.

\section{Anahtar kelimeler: Kıyı balıķılığı, av araçları, avcılık yöntemi, Marmara Denizı}

Abstract: In this study, general characteristics and technical features of the gear used in the commercial fishery of bivalve molluscs are evaluated in the coastal areas West Black Sea, Marmara Sea and Aegean Sea of Turkey. Bivalve fisheries are assessed in three main sections by dive fishing, man power coast fishing and boat power fishing, and 8 types are determined fishing gear and methods. A total of 57 various types gears of which eight wedges, five hand rake, eight hand shovel, thirteen hand dredges, three oyster's dredges, four mussel's dredges, nine mechanical dredges and seven hydraulic dredges were identified in the research areas.

Keywords: Coastal fisheries, fishing gear, fishing method, Marmara Sea

\section{GíRiş}

Çift kabuklu yumuşakçalar denize kıyısı olan ülkelerde özellikle kıyı bölgelerinde halkın önemli geçim kaynağını oluşturmakta, doğal yataklardan avcılık veya yetiştiricilik yoluyla üretilmektedir. Dünya ticaretinde, üretimi gerçekleştirilen su ürünlerinin toplam değeri içerisinde çift kabukluların oranı \%3, toplam miktar içerisindeki oranının ise \%5,6 olduğu belirlenmiştir (FAO, 2016). Ülkemizde ise çift kabuklu üretimi, neredeyse tamamı doğal yataklardan avcılık yolu ile yapılmaktadır. Türkiye'nin yıllar nezdinde artan şekilde ilerleyen çift kabuklu yumuşakça üretimi, günümüzde toplam su ürünleri üretiminin yaklaşık \%6-7'sini oluşturmaktadır (TUIK, 2010). Bu üretimin \%67.33'ünü clam grubu (Chamelea gallina, Tapes decussatus, Ruditapes philippinarum, Donax trunculus), $\% 32.55$ 'ini kara midye (Mytilus galloprovincialis) ve \%0.12'ini diğer çift kabuklular (Ostrea edulis) oluşturmuştur.

Çift kabuklu yumuşakçalar, ülkemizin kıyısal alanlarda önemli balıkçılık alanlarına sahip ürünlerdir. Bu ürünler, Batı Karadeniz, Marmara ve Ege Denizi'nde türden türe farklıık göstermekle beraber, genellikle 0-20 m derinlikler konturlarında yoğun şekilde dağılım göstermektedir. Özellikle Marmara
Denizi, Akdeniz ve Karadeniz'in etkisinde olması nedeniyle, çift kabuklu yumuşakçalar için avcılık alanlarının fazla, ürünlerin bol ve çeşitli olmasına imkân sağlamaktadır. Çift kabuklu stoklarının dağılım yoğunluğunun kıyısal alanlarda yoğunlaşması, balıkçılığın küçük teknelerle ya da kıyıdan balıkçı yardımıyla yapıımasına ve gelişmesine sebep olmuştur (Tokaç ve Çolakoğlu, 2012).

Çift kabuklu yumuşakça avcılığı, aktif ya da pasif av araçları kullanılarak yapılmaktadır. Aktif av aracı olarak, genellikle insan ya da tekne gücü yardımıyla dip sürükleme araçları (dreç, el dreci, el tırmığı vb.) kullanılarak yapılmaktadır. Pasif avcılık ise, dalgıç yardımıyla ürünlerin toplanması şeklinde gerçekleştirilmektedir. Çift kabuklu avcılığının yapıldığı kıyı alanlarında (özellikle 2-20 m derinliklerde) kullanılan aktif dip sürükleme av araçları (mekanik ve hidrolik dreç gibi) bentik ekosistemleri olumsuz etkilemekte, canlılara ciddi zararlara neden olmaktadırlar (Alves vd., 2003; Moschino vd., 2003). Bu olumsuz etki nedeniyle, ülkemizde çift kabuklu avcılığında kullanılan av araçlarının özellikle de dip sürütme av araçlarının belirlenmesi ve teknik özelliklerinin ortaya konulması 
gerekmektedir.

Türkiye'deki çift kabuklu yumuşakça avcilığının yapısal sorunları (av araçlarının standardizasyonu, sınıflandırıması, teknolojileri, kayıt altına alınması vb.), mevcut kaynakların rasyonel bir şekilde işletilmesinin temini, avcılık ve üretim planlamaları gibi genel sayllabilecek konularda sorunları giderebilecek ve çözüm önerileri oluşturabilecek bilgilere intiyaç duyulmaktadır. Bu kapsamda, Gıda Tarım ve Hayvancııık Bakanlığı tarafından "4/1 Numaralı Ticari Amaçı Su Ürünleri Avcılığının Düzenlenmesi” hakkındaki tebliğle çift kabuklu yumuşakçaların bazı türlerinin avcilığında kullanılan av araçlarına yönelik bazı düzenlemeler getirilmiştir. Ancak, araştırmalarla bu bilgilerin güncellenmesi ve eksiklerin tamamlanması gerekmektedir. Ülkemizde, çift kabuklu yumuşakça avclığında kullanılan av araçları ve yöntemlerine ilişkin çeşitli yayınlar bulunmaktadır. Bu yayınlarda, çift kabukluların avcılığı ve avlanma teknikleri genel bilgiler şeklinde verilmiş olup (Hoşsucu, 2000; Dalgıç vd., 2005 Doyuk, 2006), ayrıntılı olarak sadece Tokaç ve Çolakoğlu (2012)'nun yaptığı çalışmada verilmiş̧tir.

Çift kabuklu yumuşakça av araçlarının teknik özellikleri ile avcllıkta kullanılan yöntemlerin belirlenmesi, günümüzde sürdürülebilir ve sorumlu balıkçılık açısından büyük önem arz etmektedir. Bu nedenle bu çalışmada, ülkemizde ekonomik öneme sahip çift kabukluların avclığında kullanılan av araç ve gereçlerinin teknik özellikleri ile avlanma yöntemleri yeniden değerlendirilmiş, sorunlar tartışılmışıır.

\section{MATERYAL VE METOT}

Bu çalışma, Ege Denizi (İzmir'in Inciraltı ve Bostanlı-Degaj), Marmara Denizi (Çanakkale'nin Kepez, Eceabat, Şevketiye ve Denizkent; Balıkesir'in Misakça ve Bandırma; İstanbul'un Rumeli Kavağı ve Şile) ve Batı Karadeniz'in (Kocaeli'nin Kefken; Kastamonu'nun Cide) çift kabuklu yumuşakça avcılığının yoğun yapıldığı bölgelerde S.S. Su Ürünleri Kooperatifleri, balıkçılar ve firmalarla görüşülerek gerçekleştirilmiş̧ir. Araştırmada, avclıkta kullanılan av araçlarının yerinde tespiti yapılarak, her bir av aracının teknik özellikleri çıkartımış ve ilgili formlara kaydedilmiștir. Çift kabuklu yumuşakça avcılığında kullanılan yöntemler üç ana başlık altında değerlendirilmiş, her biri kendi içerisinde detaylandırıımışır.

\section{BULGULAR}

\section{Dalma Yöntemi ile Avcılık}

Dalarak toplama yöntemi, genellikle Ege ve Marmara Denizi'nde kara midye (Mytilus galloprovincialis), istiridye (Ostrea edulis), akivades (Tapes decussatus ve Ruditapes philippinarum), beyaz kum midyesi (Chamelea gallina), kidonya (Venus verrucosa) ve tarak (Pecten sp.) gibi ekonomik değeri yüksek çift kabukluların avcıı̆ğında yoğun şekilde kullanılmaktadır. Balıkçı, teknede mevcut bulunan kompresörün verdiği hava yardımıyla deniz dibindeki çift kabukluları toplayarak filede biriktirir, filenin dolması ile tekneye çıkarır. Ayrıca, SCUBA dalış ve şnorkel ile avcılık yapan dalgıçlarda bulunmaktadır. Bu yöntemlere ek olarak, türlere özel geliştirimiş teknikler aşağıda açıklanmıştır.

\section{Kama ile Avcılık}

Çift kabuklu yumuşakçalardan özellikle akivades (Tapes decussatus, Ruditapes philippinarum) ve beyaz kum midyesi (Chamelea gallina) kendilerini kuma gömerek yaşam faaliyetini devam ettirdiklerinden, kama ile avclık tercih edilmektedir. Balıkçı, teknede çalışan kompresörün verdiği hava yardımıyla ile deniz dibinde rahatça dolaşarak bu türlerin yerini tespit eder, daha sonra kamayı kuma batııı çıkararak ürünlerin avcılığı yapar ve ürünleri file de biriktirerek tekneye çıkarır.

Ayrıca, balıķ̧ı deniz dibinde tespit ettiği akivades ve beyaz kum midyesini eli ile kumu hareketlendirerek kumun dağıImasını sağlayarak da ürünleri toplayabilmektedir (Tokaç ve Çolakoğlu, 2012). Bu yöntemlerle avclık, daha çok Izmir'in Bostanlı-Degaj, Balıkesir'in Bandırma ve Misakça bölgelerinde yapılmaktadır. Bu bölgelerde avcılıkta kullanılan toplam 8 adet kama tespit edilmiş olup, teknik özellikleri incelendiğinde bölgeden bölgeye boyutsal farkllıkların olduğu görülmüştür. İzmir Bostanlı-Degaj ve İnciraltı avcllık bölgelerinde, 5 adet kamanın ölçümü gerçekleştirimiş̧ olup, kamanın sapı 15-16 cm ve kamanın toprağa giren metal kısmı 13-15 cm arasında değişmiştir. Balıkesir'in Bandırma ve Misakça bölgelerinde ise 3 adet kamanın teknik özellikleri belirlenmiş, kamanın sapı 13$15 \mathrm{~cm}$ ve kamanın toprağa giren metal kısmı ise $12-13 \mathrm{~cm}$ arasında değişmiştir.

\section{El Tırmığı ile Çıkartma Yöntemi}

Çift kabuklulardan kidonya (Venus verucosa) ve japon akivades (Ruditapes philippinarum) avcllığında kullanılan el tırmığı, dalgıç yardımıyla deniz dibinde zemini tarayarak ürünleri çıkarır ve fileye doldurur. Çanakkale'nin Gelibolu bölgesinde 3 ve Balıkesir'in Bandırma bölgesinde 2 adet olmak üzere toplam 5 adet el tırmığının ölçümü gerçekleştirilmiştir. Canakkale ve Balıkesir bölgelerinde el tırmığının teknik özellikleri; av aracının sapı $12-15 \mathrm{~cm}$, diş uzunluğu $4-6 \mathrm{~cm}$, diş sayısı 3 adet ve diş aralığı $1-2 \mathrm{~cm}$ olarak belirlenmiş ve boyutlarında bölgeden bölgeye farklııkların olmadığı belirlenmiştir.

\section{Kıyıdan İnsan Gücü ile Avcılık}

\section{Elekli Kürek Yöntemi}

$\mathrm{Bu}$ yöntem, özellikle akivades (Tapes decussatus, Ruditapes philippinarum) ve beyaz kum midyesi (Chamelea gallina) avcılığında kullanıımaktadır. Elekli kürek, balıkçının ayakları yardımıyla denizde kumluk zemine girmesi sağlanır, daha sonra bu kürek su içinde sallanarak ürünlerin elekleri nedeniyle kürek üzerinde kalması sağlanır. Kürekte kalanlar arasından ürünler seçilerek balıkçının yanında bağlı torbada biriktirilmektedir (Şekil 1). İzmir'in İnciraltı ve Bostanlı ile Balıkesir'in Bandırma kıyısal avcılık alanlarında, balıkçılarla yapılan görüşmelerde 8 adet elekli kürek tespit edilmiştir. İzmir bölgesinde 5 ve Balıkesir bölgesinde ise 3 adet olmak üzere ölçümü gerçekleştirilen elekli tırmıklarının teknik özellikleri 
sırasıyla; ağız genişliği 40-44 cm, elek boyu 32-36 cm, elek arka genişliği $28-32 \mathrm{~cm}$, elek göz açıklı̆ı 6-8 mm, elek yan kenarları 6-8 mm, bıçak kısmı 4-5 cm, sap boyu $110-120 \mathrm{~cm}$ ve ayaklık (sağ-sol) 4-8 cm olarak belirlenmiştir. Teknik özellikler incelendiğinde, av aracının boyutlarında bölgeden bölgeye küçük farklııkların olduğu görülmüştür.

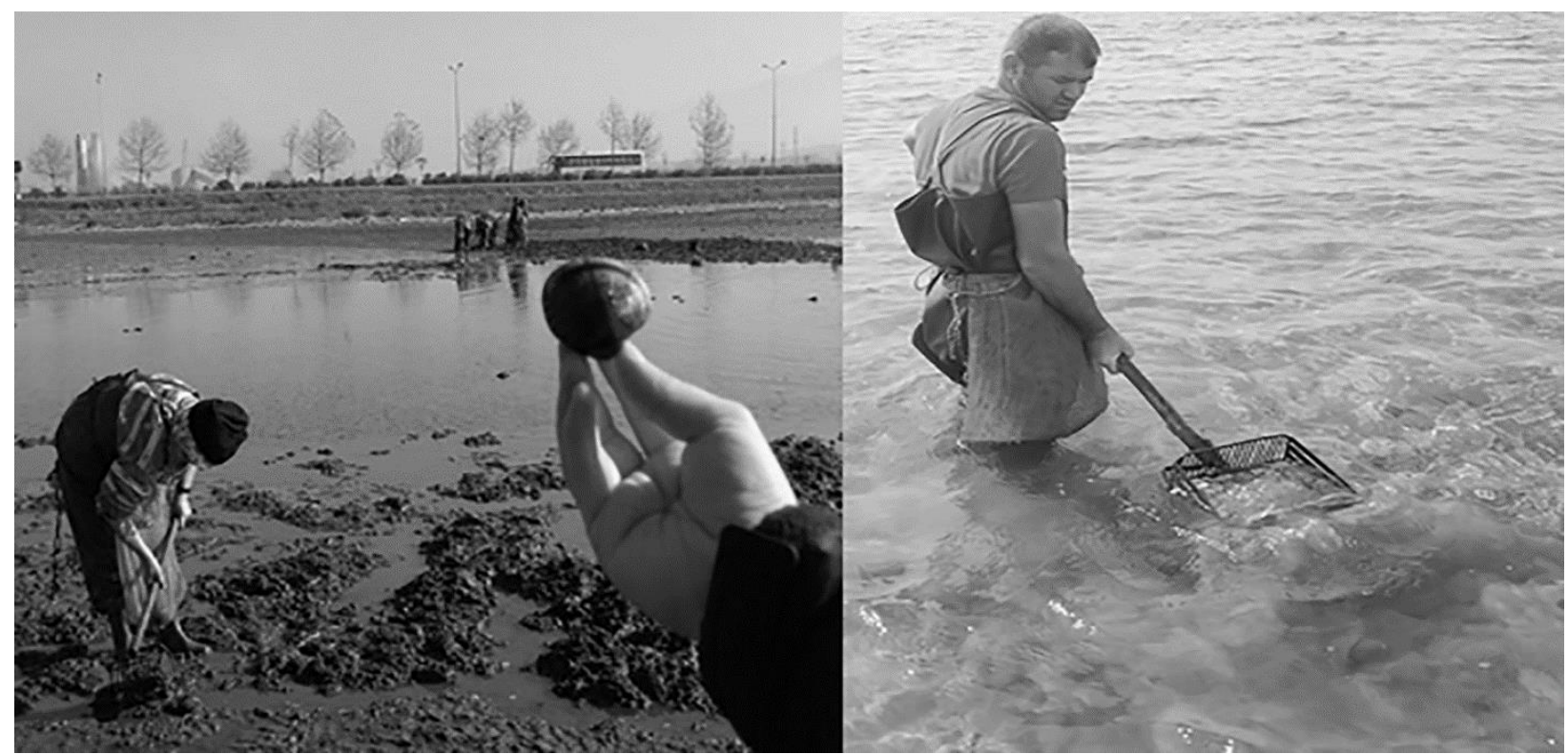

Sekil 1. Avcılıkta kullanılan elekli kürek

Figure 1. The sieving shovel used in fisheries

\section{El Dreci ile Avcilık}

Kum şırlanı (Donax trunculus) avcılığında kullanılan el drecinin ucunda bıçak ve elek, arkada ise ince örgülü file torba bulunmaktadır. Balıkçının bu av aracını tutması için 120-130 cm'lik dreç çeki kolu ve bele bağlamak için kemer bulunmaktadır. Balıkçı, kemeri beline bağlayarak çeki kolu yardımılla el drecini kendine doğru çekerek avcılığı yapar (Şekil 2). Drecin filesi dolunca kıyıya çıkararak torbayı boşaltır (Çolakoğlu, S., 2011). Kum şırlanı avcilığı, Marmara Denizi'nde özellikle Denizkent, Misakça, Karacabey, Silivri ve Şarköy bölgesinde, 1-2 m derinlikte kumsal alanlarda yapılmaktadır.
Araştırma kapsamında bölgede bu ürünü işleyen firmalar ve avcılığını yapan balıkçılarla yapılan görüşmelerde belirlenen, toplam 13 adet el drecinin teknik özellikleri belirlenmiş̧ir. El drecinin yapısal özellikleri bölgeden bölgeye herhangi bir farklılık göstermemiş olup, sadece küçük oranlarda boyutlarında değişikliklerin olduğu tespit edilmiştir. Marmara Denizi'nde avcılığın yapıldığı bölgelerde ölçümü gerçekleştirilen el dreçlerinin teknik özellikleri; ağız genişliği $56-60 \mathrm{~cm}$, ağız yüksekliği 10-12, elek boyu $50-60 \mathrm{~cm}$, elek göz açıkığı 6-8 mm, ağız bıçak kısmı 5-6 cm, dreç çeki kolu 120$130 \mathrm{~cm}$ ve dreç arka genişlik $28-30 \mathrm{~cm}$ olarak belirlenmiştir.

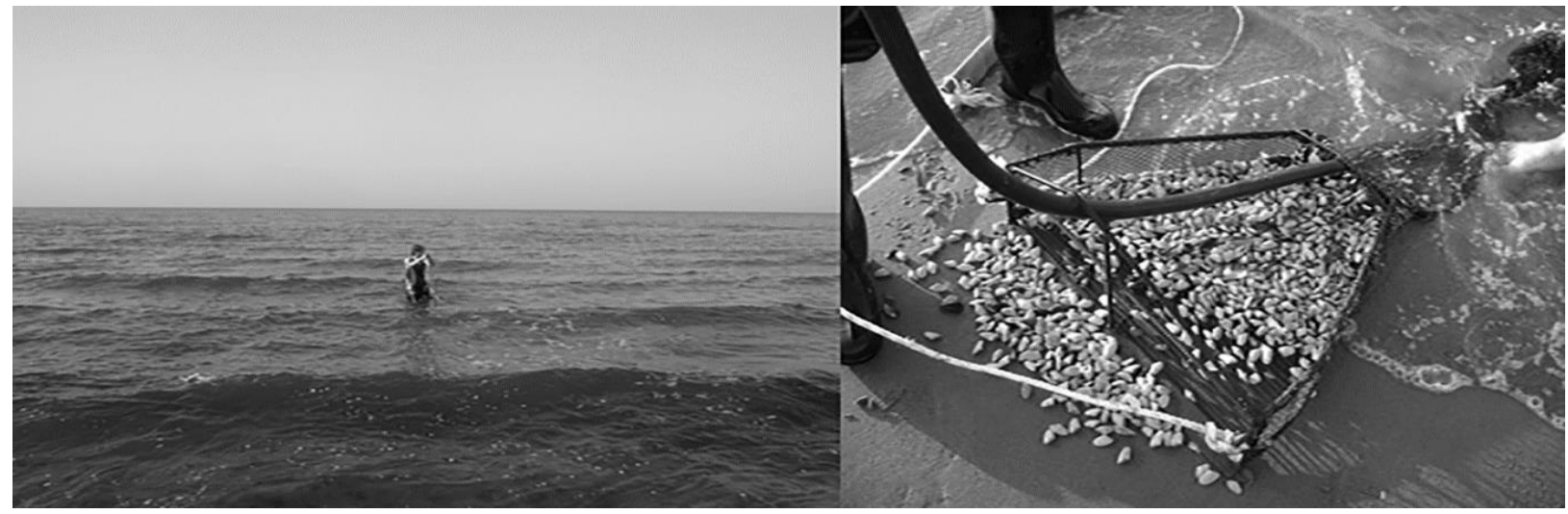

Şekil 2. Kum şırlanı avcılığında kullanılan el dreci

Figure 2. The hand dredge used to harvest wedge clam (Donax trunculus) 


\section{Tekne Gücü ile Avcılık}

Sürütme av aracı olan dreç; ağ torba, çerçeve ve çekilme halatı olmak üzere üç bölümden oluşmaktadır. Torba şeklinde olan ağın ağız kısmını açık tutmaya yarayan dikdörtgen veya yarım ay şeklinde demirden bir çerçeve bulunmaktadır. Demir çerçevenin zemine gelen tarafında, deniz dibini taramaya elverişli bıçak veya dişler bulunmaktadır. Avlanan çift kabuklu türüne göre, istiridye dreci, kara midye dreci ve kum midyesi dreci şeklinde sınıflandırılmıştır.

\section{İstiridye Dreci}

Dreç, yarım ay şeklinde bir demir çerçeveye bağlı bir torba ve üç koldan ibaret çeki demirinden oluşmaktadır. Demir çerçevenin alt kısmı deniz dibini kazımak için tasarlanmış olup, bıçak şeklinde yapılmıştır (Şekil 3). Bu av araçları ile, Marmara Denizi'nde 2-20 m derinliklerdeki kıyısal sularda istiridye avcılığı yapıldığı belirlenmiştir.

Araştırmanın yapıldığı Çanakkale'nin Kepez bölgesinde 2 adet ve İstanbul'un Rumeli Hisarı bölgesinde 1 adet olmak üzere, toplam 3 adet istiridye drecinin teknik özellikleri belirlenmiştir. Dreçlerin ağız genişliği 100-120 cm, dreç çek demiri $100-120 \mathrm{~cm}$, yarım ay çember uzunluğu $200 \mathrm{~cm}$, torba uzunluğu 2-3 m ve torba ağ gözü açıklığı 40-60 mm arasında değiştiği tespit edilmiştir.

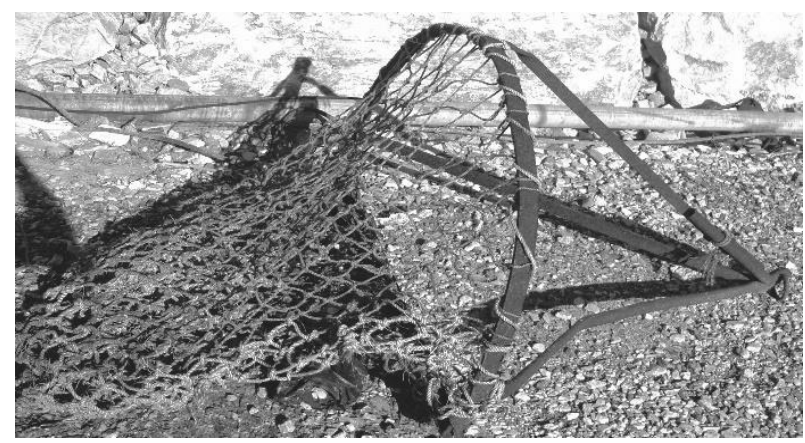

Şekil 3. Marmara Denizi'nde kullanılan istiridye dreci (Fotoğraf: Tokaç ve Çolakoğlu, 2012)

Figure 3. Oysters dredge used in Marmara Sea (Photos by Tokaç and Çolakoğlu, 2012)

\section{Kara Midye Dreci}

Dreç, dikdörtgen veya yarım ay şeklinde bir demir çerçeveye bağlı ağ torba ve çeki demirinden meydana gelmektedir (Doyuk, S.A., 2006). Genellikle Çanakkale'nin Eceabat ve Kepez ile İstanbul'un Rumeli Kavağı bölgelerinde, kara midyelerin yoğun olarak bulunduğu 2-20 m derinliklerdeki kıyısal alanlarda dreç çekimi yapılmaktadır (Şekil 4). Çanakkale bölgesinde 3 adet ve İstanbul bölgesinde 1 adet olmak üzere, toplam 4 adet kara midye drecinin teknik özellikleri belirlenmiştir. Rumeli Kavağı'nda teknik özellikleri belirlenen drecin ağız genişliği $70 \mathrm{~cm}$, dreç çeki demiri $90 \mathrm{~cm}$, yarım ay çember uzunluğu $120 \mathrm{~cm}$, diş sayısı 5 ve torba uzunluğu $2 \mathrm{~m}$ Çanakkale'deki dreçlerin ise ağız genişliği 50-60 cm, dreç çeki demiri $70-80 \mathrm{~cm}$, yarım ay çember uzunluğu $100-110 \mathrm{~cm}$, diş sayısı 3 ve torba uzunluğu 1,5-2 m arasında olduğu tespit edilmiştir. İki bölge arasında tespiti yapılan dreçlerin boyutlarında farklııkların olduğu görülmüştür.

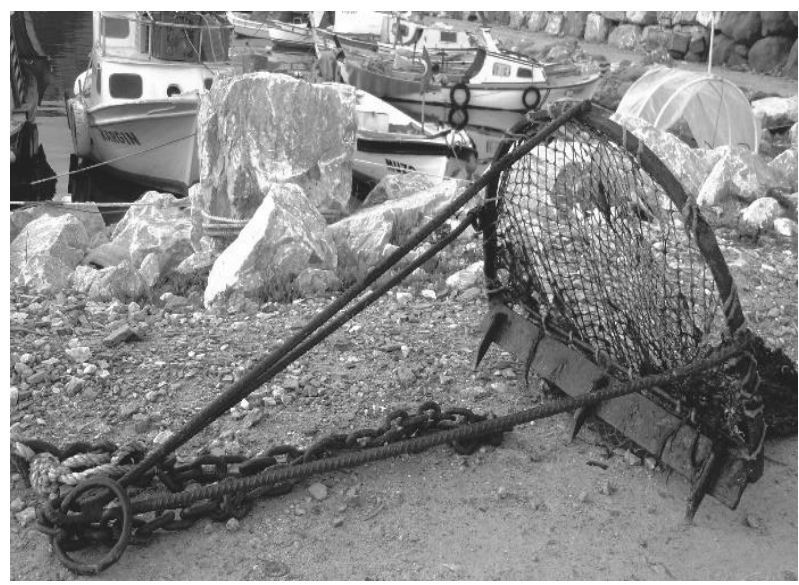

Şekil 4. Kara midye dreci (Fotoğraf: Tokaç ve Çolakoğlu, 2012)

Figure 4. The mussels dredge (Photos by Tokaç and Çolakoğlu, 2012)

\section{Beyaz Kum Midyesi Dreci}

Beyaz kum midyesi dreci, dikdörtgen şeklinde demir bir çerçeveye bağı ağ torba ve çeki düzeninden oluşmaktadır. Ayrıca, demir çerçevenin zemine gelen kısmı deniz dibini taramak için tarak şeklinde dişlerden yapılmıştır. Avcılık, motor gücüyle tekne yardımıyla çekilerek yapılmaktadır. Çekim esnasında drecin dişlerinin zemine 10-15 cm kuma girmesi ile ürünlerin torbada toplanması ile istihsal yapılmaktadır. Beyaz kum midyesi avcılığında, mekanik ve hidrolik dreçler olmak üzere iki tip dreç kullanılmaktadır.

\section{Mekanik Dreç}

Mekanik drecin ana yapısı ızgara elekli ve ucunda dişleri bulunmakta, arkada 1-2 m uzunluğunda ağ torba ve drecin alt yanlarında zeminde kayması için kızaklar (tekerlek) bulunmaktadır (Şekil 5). Dreç, kapasitesi ve büyüklüğüne göre insan gücü ya da motor gücüyle tekneye alınmaktadır. Genellikle, Marmara Denizi'nin Şevketiye, Kemer, Misakça, Gelibolu ve Tekirdağ Kumbağ ile Batı Karadeniz'in Kefken ve Şile bölgelerinde 3-20 m derinliklerdeki kıyısal alanlarda kullanılmaktadır. Marmara Denizi'nde 3 adet ve Batı Karadeniz'de 6 adet olmak üzere toplam 9 adet mekanik drecin teknik özellikleri belirlenmiştir. Bu dreçlerin zeminde kayması için, bazı bölgelerde tekerlek bazılarında ise kızakların kullanılması şeklinde yapısal farklılıklar olduğu görülmüştür. Marmara Denizi ve Batı Karadeniz'de ölçümleri yapılan dreçlerin teknik özellikleri sırasıyla; ağız genişliği $60-70 \mathrm{~cm}$ ve $80-90 \mathrm{~cm}$, ağız yüksekliği $35-40 \mathrm{~cm}$ ve $40-55 \mathrm{~cm}$, elek boyu $50-60 \mathrm{~cm}$ ve $70-80 \mathrm{~cm}$, elek göz açıklığı 8-10 mm, diş uzunluğu 8-10 cm, diş aralığı 8-10 mm ve diş sayısı 25-30 adet ve 35-45 adet olarak belirlenmiştir. Avcılığın yoğun yapıldığı Kefken ve Şile bölgelerinde daha büyük boyutlu dreçlerin kullanıldığı tespit edilmiştir. 


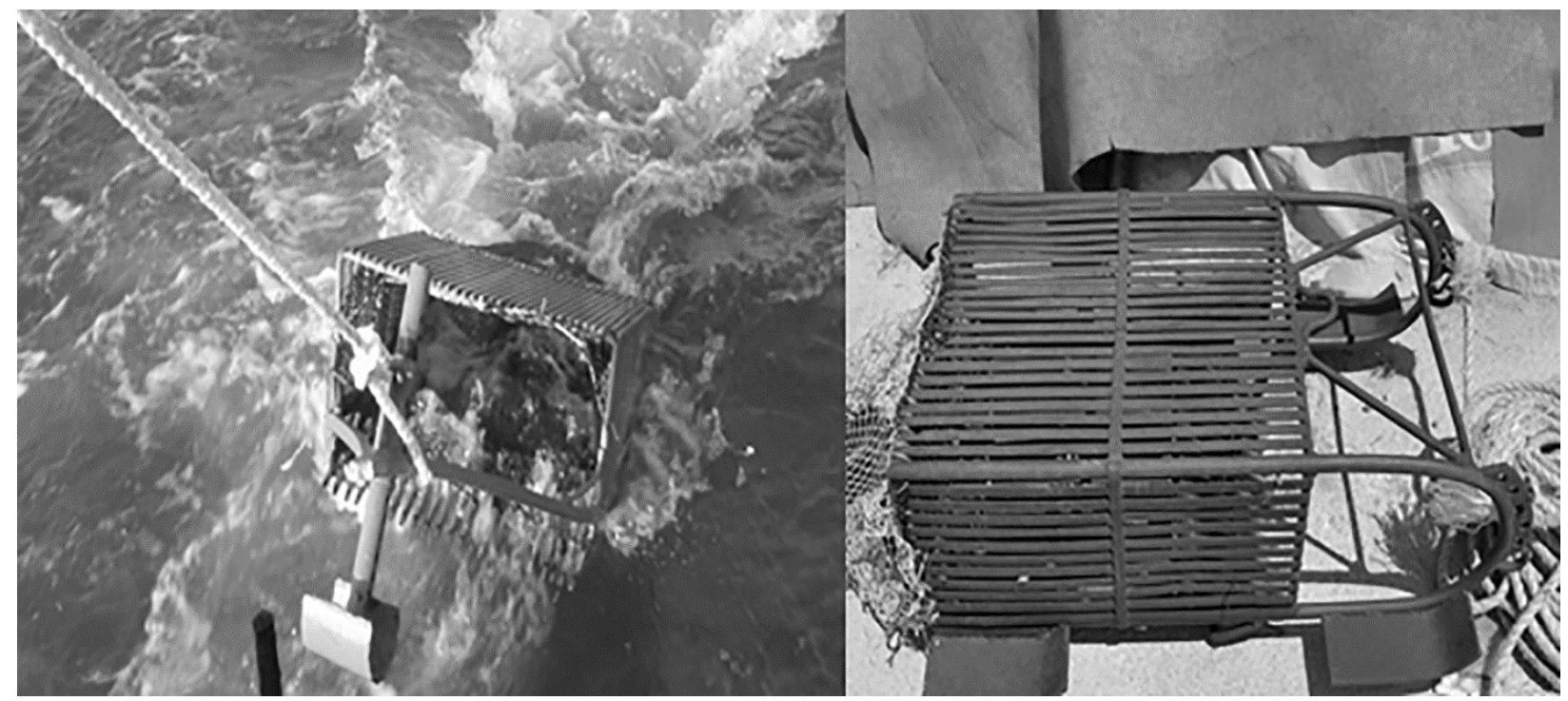

Şekil 5. Avcılıkta kullanılan mekanik dreç.

Figure 5. Mechanical dredge used in fisheries

\section{Hidrolik Dreç}

Ülkemizde, beyaz kum midyesi avcilığında tekne büyüklüğüne göre farklı boyutlarda hidrolik dreçler kullanılmaktadır. Hidrolik dreç ve otomatik elek sistemleri teknenin kıç tarafında konumlandırımıştır. Dreç suya indirildikten sonra teknede mevcut bulunan farklı bir dizel motordan sağlanan güç yardımıyla drece bağlı hortum sistemi ile zemine basınçlı su verilerek 1,5-2 knot hızla çekim gerçekleştirilmektedir (Dalgıç vd., 2005). Basınçlı su verilmesinin ana amacı, zemindeki mevcut ürünleri kaldırarak drece daha kolay girmesini sağlamaktır (Şekil 6).
Ülkemizde, Batı ve Orta Karadeniz'in Şile, Kefken ve Cide bölgelerinde 5-20 m derinliklerdeki kıyısal alanlarda beyaz kum midyesi avcılığında kullanılmaktadır. Araştırma kapsamında Şile'de 3 adet, Kefken'de 3 adet ve Cide'de 1 adet olmak üzere toplam 7 adet hidrolik drecin teknik özellikleri belirlenmiş, boyutsal farkılıkların olduğu tespit edilmiştir. Şile, Kefken ve Cide bölgelerinde tespiti yapılan dreçlerin özellikleri sırasıyla; ağız genişliği 2-5 m, 3-5 m ve 3 m uzunluğunda; ağız yüksekliği $35-55 \mathrm{~cm}, 40-55 \mathrm{~cm}$ ve $45 \mathrm{~cm}$; elek göz açıkığı 7-8 mm, 7-8 $\mathrm{mm}$ ve $8 \mathrm{~mm}$; diş uzunluğu $9-10 \mathrm{~cm}$ ve diş aralıkları $8-10 \mathrm{~mm}$ arasında belirlenmiştir.

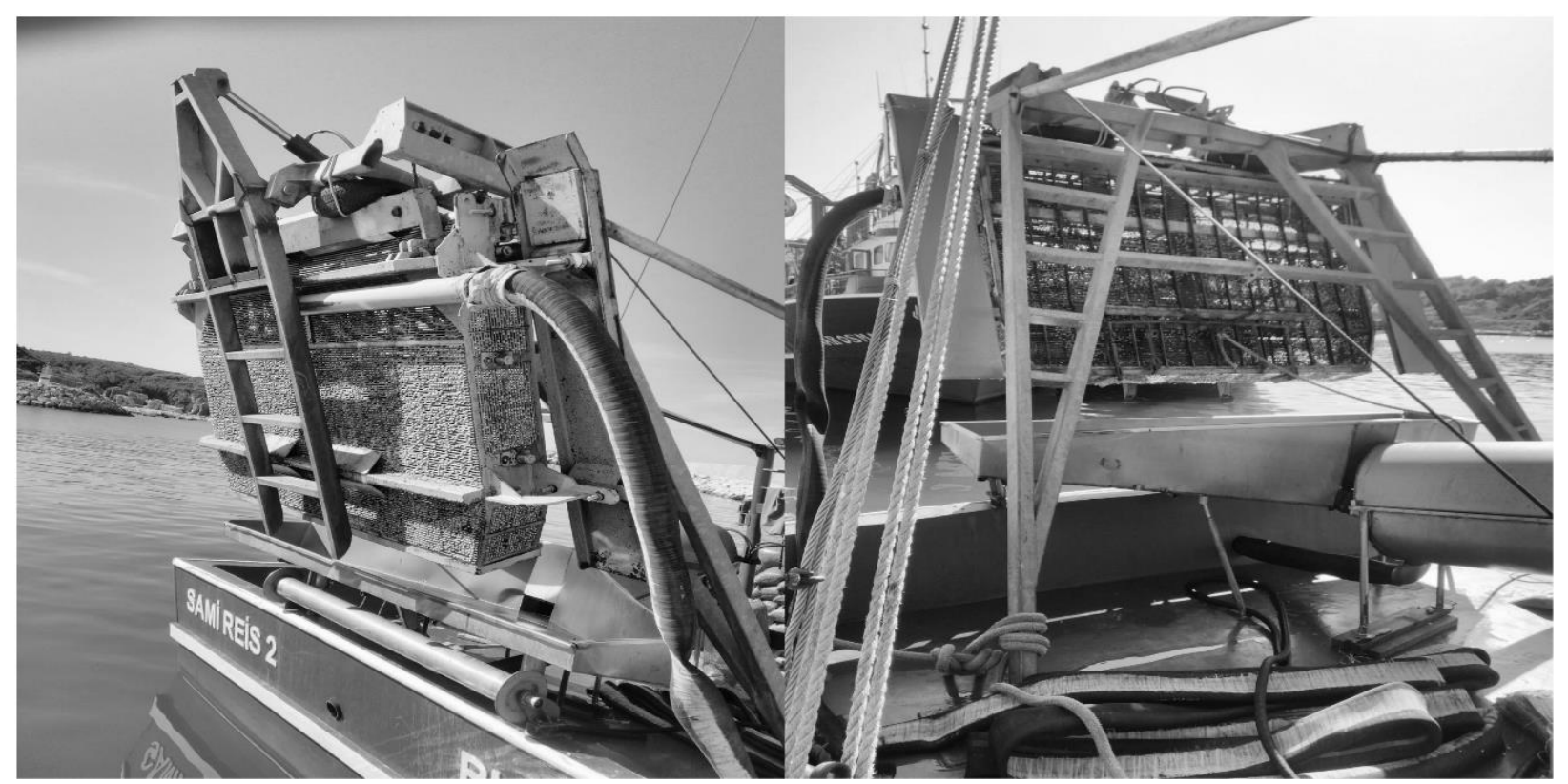

Şekil 6. Avcılıkta kullanılan hidrolik dreç

Figure 6. Hydraulic dredge used in fisheries 


\section{TARTIŞMA VE SONUÇ}

Bu çalışmada, Türkiye'de çift kabuklu yumuşakça avcılığının yoğun şekilde yapıldığı İzmir'in İciraltı ve BostanlıDegaj; Çanakkale'nin Kepez, Eceabat, Şevketiye ve Denizkent; Balıkesir'in Bandırma ve Misakça; İstanbul'un Rumeli Kavağı ve Şile, Kocaeli'nin Kefken ve Kastamonu'nun Cide bölgelerinde balıkçılar ve Su Ürünleri Kooperatifleri ile birebir görüşmeler yapılarak gerçekleştirilmiştir. Araştırmada, 8 adet kama ve 5 adet el tırmığı olmak üzere toplam 13 adet dalarak; 8 adet elekli kürek ve 13 adet el dreci olmak üzere toplam 21 adet kıyıdan insan gücü ile ve 3 adet istiridye, 4 adet kara midye, 9 adet mekanik dreç ve 7 adet hidrolik dreç olmak üzere toplam 23 adet tekne gücü ile avcılık yapan av aracının teknik özellikleri saptanmıştır. Ayrıca, bu av araçlarının kullanım yöntemleri ile hedef türleri de tespit edilmiştir.

Ülkemizde çift kabuklu yumuşakça avcılığında kullanılan av araçları ile ilgili farklı bölgelerde araştırmalar yapılmış, çalışmaları daha çok beyaz kum midyesi avcılığı oluşturmuştur. Tokaç ve Çolakoğlu (2012) farklı bölgelerde çift kabuklu avcılığında kullanılan on iki adet av aracı tanımlamış, çalışmada sadece bir av aracı üzerinde yapılan ölçümler sonucunda değerlendirmeler yapıımış kendi içinde yapısal ve bölgesel farkıııklar ile ilgili bilgiler eksik kalmıştır. Yapılan bu çalışmada, toplam 57 adet av aracının teknik özellikleri belirlenmiş ve her bir av aracı kendi içinde değerlendirilerek yapısal farklııklar ile bölgesel kullanımlar ortaya konulmaya çalışılmıştır. Bilecik (1986) Kuzey Marmara Denizi'nde beyaz kum midyesi avcılığında kullanılan hidrolik drecin mekanik drece göre yararları ve zararlarını incelemiştir. Cebeci (1994) kum midyesi stoklarının korunması için $30 \mathrm{~mm}$ boydak ürünlerin avlanmasının uygun olacağı, bunun için dreç ağız açıklığının $80 \mathrm{~cm}$, ağız derinliğinin $20 \mathrm{~cm}$, diş aralığının $2 \mathrm{~cm}$, kafes çubuğu aralığının $1 \mathrm{~cm}$, drece bağlı torbanın boy uzunluğunun $1 \mathrm{~m}$, göz açıklığının $1 \mathrm{~cm}$, avlanma boyunun da 30 mm olması gerektiğini belirlemiştir. Atay (1995), beyaz kum midyesinin avlanma teknikleri ve stokların kalitatif özelliklerinin korunması üzerine araştırmalar yapmış ve hidrolik drecin mekanik drece oranla stoklara daha az zarar verdiğini belirlemiştir. Dalgıç vd. (2005) ve Dalgıç (2006) Batı ve Orta Karadeniz'de yapılan çalışmada, beyaz kum midyesi avcılığında kullanılan mekanik ve hidrolik drecin av potansiyeli, teknik özellikleri ile türün populasyon yapısı değerlendirilmiştir. Çolakoğlu (2011) ise, Güney Marmara'da beyaz kum midyes ve kum şırlanının ticari avcılığında kullanılan mekanik ve el drecinin teknik özellikleri, av potansiyelleri ile ürünlerin populasyon yapılarının belirlenmesi ile ilgili bölgesel çalışmalar gerçekleştirmiştir. Ayrıca, Doyuk (2006) tarafından Çanakkale bölgesinde su ürünleri avcılığında kullanılan av araçlarından kara midye drecinin teknik özelliklerini tespit etmiştir.

Çift kabuklu yumuşakçalar ülkemiz denizlerinin kıyısal alanlarında yoğun şekilde yayılım göstermekte olup, özellikle Marmara Denizi tür çeşitliliği yönünden verimlilik arz etmektedir. Balıkçılar, İzmir bölgesinde akivades; Çanakkale ve Balıkesir bölgelerinde kara midye, istiridye, japon akivades, beyaz kum midyesi ve kum şırlanı; İstanbul, Kocaeli ve
Kastamonu bölgelerinde ise beyaz kum midyesi ve kum şırlanı hedef tür olarak belirlemişlerdir. Bu türlerin avcılıkları, genel av yasakları (üreme dönemi) ve avcılık alanlarının açılıp kapanmasına bağıı olarak, bahsedilen av araçları ile dönemsel olarak yapılmaktadır.

Çift kabuklular sularda planktonları süzerek beslendiklerinden beraberinde mikroorganizma ve kimyasal maddeler gibi zararlı bileşenleri de bünyelerine alabilmekte, biriktirdikleri bu unsurlar nedeniyle insan tüketiminde tehlike oluşturabilmektedirler. Bu nedenle, avcllık alanlarının istihsale açılmadan önce çevresel koşulların takip edilmesi ve alanda ürünlerin tüketim açısından uygunluğu rutin şekilde izlenmesi önemli bir gereklilik ve tek seçenek olarak ortaya çıkmaktadır. Ülkemizde, Gıda, Tarım ve Hayvancılık Bakanlığı tarafından avcılık alanlarında mikrobiyolojik, biyotoksin, ağır metal, toksik alg ve su kalitesi analizleri periyodik olarak yapılmakta, eğer sonuçlar uygun ise avcılığa açılmaktadır. Bakanlığın belirlediği, İzmir'de 2 adet akivades; Balıkesir'de 1 adet kum şırlanı ve 3 adet japon akivades; İstanbul'da 1 adet kara midye ve 2 adet beyaz kum midyesi; Sakarya'da 3 adet, Düzce'de 1 adet, Kocaeli'nde 2 adet ve Kastamonu'da 3 adet beyaz kum midyesi olmak üzere toplamda 18 adet avcılık alanı bulunmaktadır (Anonim, 2017). Özellikle akivades, kara midye ve kum şırlanı avcııık alanlarının yeterli olmaması balıkçılığı ve bu ürünleri işleyip satışa sunan işletmeleri olumsuz yönde etkilemektedir. Bu durum, resmi olarak avcılık alanı ilan edilmeyip yoğun şekilde ürünlerin olduğu bölgelerde kaçak avcılığın artmasına sebebiyet vermekte, insan tüketimine uygun olmayan ve güvensiz ürünlerin piyasaya verilmesine neden olmaktadır.

Çift kabuklu yumuşakça avcılığına Gıda Tarım ve Hayvancılık Bakanlığı tarafından "4/1 Numaralı Ticari Amaçlı Su Ürünleri Avcılığının Düzenlenmesi Hakkındaki Tebliğ” kapsamında bazı sınırlama ve düzenlemeler getirmiştir. Bu tebliğde avcılık koordinatlarla belirlenmiş olup, bazı bölgelerde tamamen yasaklanmıştır. Ayrıca, türe özgü üreme dönemi yasakları (akivades, kidonya, istiridye, tarak ve kum şırlanı için 15 Nisan-31 Ağustos; kara midye için 15 Nisan-30 Haziran) ile avcılığında kullanılan araç ve gereçlerine yasaklar getirilmiştir. Bunlar, beyaz kum midyesi avcılığında kullanılan algarna ve dreçlerin; 1) Ağız açıklığı 80 cm'den, ağız derinliği 20 cm'den büyük, torba boy uzunluğu ise $200 \mathrm{~cm}$ 'den fazla olamaz; hidrolik dreçlerin ağız açıklıkları $350 \mathrm{~cm}$ 'den, boyları 300 cm'den fazla olamaz, 2) Dreçlerde ve eleklerdeki metal yuvarlak çubuklar arasındaki mesafe $8,5 \mathrm{~mm}$ 'den küçük olamaz; akivades avcılığında kullanılan eleklerde elek göz açıklığı 24 mm'den, kidonya istihsalinde kullanılan eleklerde elek göz açıklığı 30 mm'den küçük olamaz; kum şırlanı avcılığında kullanılan eleklerde elek göz açıklığı 1,6 cm'den küçük olamaz şeklinde yasaklar getirilmiştir.

Ekonomik değeri yüksek olan çift kabuklu yumuşakçalar, Ege, Marmara ve Karadeniz'in kıyı kesimlerinde yöre halkı ve kıyı balıkçısının geçim kaynağıdır. Ayrıca, bu ürünleri arındıran veya işleyen birçok su ürünleri işletmesi mevcut olup, iç ve dış piyasaya ( $A B$ ülkeleri) satış yapabilmektedirler. Bu nedenle, bu denli ekonomik potansiyele sahip çift kabuklu üretiminin 
desteklenmesi için, türe göre avcılık alanlarının belirlenerek stok tespitlerinin yapılması, populasyon yapılarının araştırılması ve izleme programlarının uygulanması büyük önem arz etmektedir.

Bunlara ek olarak stokların yönetimi ve sürdürülebilir kullanımı için, avcılıkta kullanılan av araçlarının av verimleri (CPUE), hedef dışı av oranları (by-catch) ve av araçlarının seçicilik çalışmalarının da en kısa zamanda yapılması, elde

\section{KAYNAKÇA}

Alves, F., Chicharo, L., Nogueira, A. \& Regala, J. (2003). Changes in bentic community structure due to clam dredging on Algarve cost and the importance of seasonal analysis, Journal of the Marine Biological Association of the United Kingdom, 83:719-729. doi: $10.1017 / S 0025315403007707 \mathrm{~h}$

Anonim (2017). Gıda, Tarım ve Hayvancılık Bakanlığı çift kabuklu yumuşakça üretim alanları listesi. Alıntılanma adresi:

http://www.tarim.gov.tr/Konu/994/Cift-Kabuklu-Yumusakca-UretimAlanlari (05.09.2017).

Atay, S. (1995). Kum midyesi (Venus gallina L.) biyolojisi, avclık teknikleri, stok dağılımı ve korunması üzerine bir araştırma. Yüksek Lisans Tezi, Dokuz Eylül Üniversitesi, Fen Bilimleri Enstitüsü, İzmir.

Bilecik, N. (1986). Kum midyesini (Venus gallina ) özel av aracı ile avlanmas amacıyla, Marmara Denizi'nde yapılan deneme çalışmalarına ait rapor T..K.B İstanbul İl Müdürlüğü, İstanbul.

Cebeci, M. (1994). Kuzey Marmara Denizi'nde Chamelea gallina L, 1758'nin biyometrisi ve avcılığı. İstanbul Üniversitesi Su Ürünleri Dergisi, 8: 31-66.

Çolakoğlu, S. (2011). Çanakkale Boğazı ile Batı Marmara'da kum midyes (Chamelea gallina L., 1758) ve kum şıllanının (Donax trunculus L., 1758) stok tahmini. Doktora Tezi, Ege Üniversitesi, Fen Bilimleri Enstitüsü, İzmir.

Dalgıç, G., Okumuş, İ., Ceylan, Y. \& Engin, S. (2005). Türk işi İtalya işi: Türkiye'de kum midyesi (Chamelea gallina L., 1758) avcılığı yapan teknelerin teknik ve operasyonel özellikleri. Türk Sucul Yaşam Dergisi, 414-417. edilen bu veriler değerlendirilerek yönetim stratejilerinin oluşturulmasında büyük katkı sağlayacaktır.

\section{TEŞEKKÜR}

$\mathrm{Bu}$ çalışmanın yürütülmesinde yardımlarını esirgemeyen Çanakkale, Balıkesir, İstanbul, Kocaeli ve Kastamonu S.S. Su Ürünleri Kooperatifleri ile tüm bölge balıkçılarına teşekkürü bir borç biliriz.

Dalgıç, G. (2006). Karadeniz kum midyesi Chamelea gallina (L., 1758) populasyonunun üreme periyodu ve büyüme performansının belirlenmesi. Doktora Tezi, Karadeniz Teknik Üniversitesi, Fen Bilimleri Enstitüsü, Trabzon.

Doyuk, S.A. (2006). Çanakkale bölgesinde kullanılan av araçlarının teknik özelliklerinin belirlenmesi üzerine bir çalışma. Yüksek Lisans Tezi, Çanakkale Onsekiz Mart Üniversitesi, Fen Bilimleri Enstitüsü, Çanakkale.

Food and Agriculture Organization (2016). The state of world fisheries and aquaculture. Rome, $200 \mathrm{pp}$.

Hoşsucu, H. (2000). Balıkçılık III (Avlama Yöntemleri). Ege Üniversitesi Su Ürünleri Fakültesi Yayınları Ders Kitabı, Dizin No: 59. İzmir. 87-91 s.

Moschino, V., Deppieri, M. \& Marin, M.G. (2003). Evaluation of Shell damage to the clam Chamelea gallina captured by hydraulic dredging in the Northern Adriatic Sea. Journal of Marine Science, 60:393-401. doi: 10.1016/S1054-3139(03)00014-6

Tokaç, A. \& Çolakoğlu, S. (2012). The State of The Turkish Fisheries. In Adnan Tokaç, Ali Cemal Gücü, Bayram Öztürk (Eds.), Fisheries by Species Bivalve Fisheries in Turkish Seas (pp 440-452). Turkey: Seba Digital Baskı ve Matbaacılık Turz. San. Tic. Ltd. Şti.

Türkiye İstatistik Kurumu (2010). 2010 yılı su ürünleri istatistikleri. Başbakanlık Devlet İstatistik Enstitüsü Müdürlüğü Ankara. Alıntılanma adresi: http://www.tuik.gov.tr/PreTablo.do?alt_id=1005 (05.09.2017) 